\title{
Towards a global system of monitoring the implementation of UN fundamental principles in national official statistics
}

\author{
Andreas V. Georgiou ${ }^{\mathrm{a}, \mathrm{b}}$ \\ ${ }^{a}$ Visiting Lecturer (2017), Amherst College, USA \\ ${ }^{\mathrm{b}}$ Former President of the Hellenic Statistical Authority (2010-2015), Greece \\ E-mail:avgeorgiou@yahoo.com
}

\begin{abstract}
The paper aims to advance the discussion on the need for an international-global system of review and assessment of the implementation of the UN Fundamental Principles of Official Statistics (UNFP). It introduces an analytical argument of why official statistics and their quality is a "global public good", which needs to be managed appropriately at the global level so as to achieve a socially optimal outcome. While progress has been made in promoting the UNFP, the current system of monitoring their implementation and thus the quality of official statistics in individual countries is severely limited. This is because it is a system of voluntary self-assessment and self-monitoring and thus of limited reliability and usefulness. Moreover, the peer reviews that have taken place, although helpful, do not constitute the appropriate long term solution to the issue of optimally managing the global public good of official statistics. Instead, effective compliance monitoring of the implementation of the UNFP, through regular evaluation, verification, follow-up and published reports in the form of audits by an independent international institution, is essential for rigorous, timely and harmonized implementation of the UNFP. The paper also discusses aspects of setting up the proposed international institution and global system of monitoring.
\end{abstract}

Keywords: UN Fundamental Principles of Official Statistics, national official statistics, global public good, international institution, monitoring, quality

\section{Introduction}

The foreword of the Implementation Guidelines of the United Nations Fundamental Principles of Official Statistics from 2015 [1] states that "in order for the Principles to be more than just a statement of noble intentions, we need to renew our efforts, individually and collectively, to make them the basis of our day-to-day statistical work. Implementing them in our national institutions and systems is our common challenge. In this respect, much has been accomplished in the past twenty years, but much still remains to be done." There have also been comments in international statistical fora that there is a relative void when it comes to moving from declarations and references for good practices to an appropriate reaction when problems arise and that there is a need to operationalize the UNFP. ${ }^{1}$

This paper agrees that much still remains to be done. Between the reference point of the United Nations Fundamental Principles (UNFP) ${ }^{2}$ and their implementation guidelines on the one hand and the appropriate reaction to problems with the integrity of statistics on the other hand there is a critical space that needs to be covered by taking certain determined steps. Effective compliance monitoring of the implementation of the UNFP is one such step, and a precondition for any enforcement mechanism. The question is how this com-

\footnotetext{
${ }^{1}$ Various remarks and presentations; for example Bodin [2] and Bohata [3].

${ }^{2}$ For a brief history of the origins of the UNFP see Malaguerra et al. [4].
} 
pliance monitoring should be done. This is the topic of this paper.

The paper is structured as follows. Section 2 discusses the current system of monitoring and enforcement of implementation of the UNFP. It argues that the current system is severely limited as it is effectively a system of voluntary self-assessment and selfmonitoring and thus of limited reliability and usefulness. Section 3 introduces an analytical argument of why official statistics and their quality is a "global public good" and argues that as such it needs to be managed appropriately at the global level so as to achieve a socially optimal outcome from the point of view of the world community. Section 4 discusses the peer reviews that have taken place in some countries, and although they are assessed as helpful, they are deemed not to constitute, for a number of reasons, the appropriate long term solution to the issue of optimally managing the global public good of official statistics. In Section 5, the paper argues instead that effective compliance monitoring of the implementation of the UNFP, through regular evaluation, verification, follow-up and published reports in the form of audits by an independent international institution at the global level is essential for rigorous, timely and harmonized implementation of the UNFP in the long run. It discusses various aspects of setting up the proposed international institution and the global system of monitoring the implementation of the UNFP with a view to stimulating a discussion on the specifics in this area. Section 6 discusses various arguments and concerns that may be raised against the independent international institution proposed in this paper. Section 7 summarizes some conclusions.

\section{The current system of monitoring and enforcement of implementation of the UN Fundamental Principles}

Currently the implementation of the UN Fundamental Principles is monitored via a survey conducted every ten years by the United Nations Statistical Division (UNSD) and presented at the United Nations Statistical Commission (STATCOM). The National Statistical Offices are asked to assess the implementation of the principles by themselves and by the political authorities. The results of this self-assessment are processed and presented in a document referred to as the Global Review. [5] The evidence provided by the country authorities themselves is used to assess whether and to what extent improvement in the implementation of the UNFP has taken place.

According to the Global Review, the tools for the further effective advancement of the implementation of the UNFP are advocacy at the political level, training of statisticians, the compilation of best practices and technical assistance [5]. Moreover, the UNFP Implementation Guidelines present themselves as a communication tool, a training tool, a reference point for the daily work of official statisticians and generally as advice for statistical agencies [1]. Therefore, basically only tools for self-monitoring and self-assessment are currently envisaged.

\subsection{Assessment of the current system}

The current system of monitoring the implementation of the UNFP is based on potentially incomplete or potentially biased evidence provided through selfassessment and can easily overstate the degree of implementation of the statistical principles. The 10-year self-assessment surveys used, plus the publication of the implementation guidelines for the UNFP, are undoubtedly useful to national statistical offices and other official statistics producers at the national level. However, they are inadequate in that they are not resulting in appropriate monitoring of the UNFP, and cannot by themselves constitute a robust process for improving the implementation of the UNFP.

While one could find indications that the existence of the UNFP since the 1990s and of derivative codes of practice around the world has been helpful in the implementation of statistical principles, there is clear evidence that very serious problems in the production of official statistics and the conditions in which it takes place have occurred during this period, and some problems continue to this day. This fact alone indicates that the current monitoring system does not offer the degree of deterrence that such a system should offer.

At the same time there is no reliable confirmation available that the serious problems that have happened to come to the attention of the international community are actually the only ones that have existed over the last twenty years. For example, if there are cases of significant loss of independence though pressure, politicization and coopting of institutions producing official statistics, and if the statistics produced by these institutions are not subjected to rigorous international scrutiny (such as the scrutiny of the Excessive Deficit Procedure in the EU), it is likely that significant problems with such institutions' official statistics have re- 
mained unknown or unrecognized internationally. The current system of voluntary self-assessment would not lead to the identification or deterrence of such cases.

Besides major problems with the implementation of the UNFP, even the degree of compliance with the UNFP in the case of more minor difficulties or weaknesses would not be objectively monitored with the current system of voluntary self-assessment. The natural tendency of many official statistics producers, who are part of a national public administration and of the executive branch of a national government, would be to keep some of the difficulties and weaknesses of their national experiences and set-ups of producing official statistics out of their voluntary self-assessments. Thus there is an inherent bias in the degree of compliance with the UNFP identified by the current system of monitoring.

Instead of self-assessment being effectively the endproduct of the monitoring process as in the current status quo, self-assessment should be one of various inputs into a robust review and assessment of implementation conducted by an independent party. Selfassessment would have to be supplemented by external examination, verification, rating, and follow-up monitoring.

Self-assessment and self-regulation are bound not to work adequately for a number of reasons. This is evident in cases where there is political influence and pressure on the production of official statistics. However, there is also a broad theoretic reasoning that indicates a tendency to achieve a suboptimal level of quality in official statistics and thus a weak implementation of the UNFP. The reasoning is that official statistics is a global public good and as such the level of quality of statistics produced, if left to individual countries' selfregulation, will tend to be lower than the level of quality that is optimal from a global point of view. There are externalities both on the production and the consumption side of official statistics that give rise to this result.

\section{Official statistics is a global public good}

Official statistics is a global public good as it provides non-excludable and non-rival benefits to all users.

Non-excludability means that it is technically impossible or extremely costly to exclude any individual from the consumption of the good [6]. Once a given amount of the good is available for anyone, it is available to everyone automatically and irrespective of whether any payment is made for the consumption of the good by any consumer. If a larger amount or better quality of the good is produced, it is available to everyone as well. Official statistics meets the criterion of non-excludability as official statistics are by the current practice characterizing them available to all users, irrespective of whether they have paid for it or not. At the same time, improvements in the scope of official statistics or its quality are available to all users.

The other criterion of a public good - non-rivalness is the property of a good that prevents rivalry among its consumers because consumption of the good by any one consumer does not diminish its availability to other consumers [6]. The appearance of new consumers does not lead to a correspondingly lower consumption by others, as is the case with private goods. Official statistics meets this criterion as the use of the statistics by one user does not prevent other users from using it.

However, official statistics is not just a public good for a certain geographic region or for a nation state (which it is); it is a "global public good" in the sense that it is a good which is non-rivalrous and nonexcludable throughout the whole world, as opposed to a public good which exists in just one regional area or nation state. International financial stability, climate change mitigation, global public health issues such as the elimination of infectious diseases, curtailing the proliferation of weapons of mass destruction are some examples of global public goods [7]. Official statistics and their quality would surely qualify as a global public good and the reasons are described below.

The demand for official statistics arises from the different types of users that exist and are the government and state administration of the country producing the specific statistics, but also those of partner countries in the region and of countries in other parts of the world (directly or through international organizations), the research/scientific community inside and outside the country, the domestic and international markets, the domestic public and the public of other countries.

As a public good, the demand for official statistics is not derived by horizontally summing the demand curves of the various users, as would be the case for goods that are not public (i.e., are private goods), but by vertically summing them as the given quantity and quality of official statistics is consumed simultaneously by the various users. There can be a derivation of the demand curve for official statistics from the declining marginal benefit curves of the individual users. One can schematically depict the marginal private benefits 
of various levels of quality of official statistics. The height of the curve indicates the maximum value or price the user would be willing to pay for increases in the quality of official statistics. Consecutive increases in the quality of official statistics would fetch declining prices. However, this is a pseudo-demand curve because in reality official statistics are not offered in the market. The various users' pseudo-demand curves are summed vertically to produce the marginal social benefits associated with the various levels of quality of official statistics. Thus, in a two user world, a given level of quality yields a marginal social benefit, which is $\mathrm{MSB}=\mathrm{MPB}_{\mathrm{U} 1}+\mathrm{MPB}_{\mathrm{U} 2}$, where $\mathrm{MPB}_{\mathrm{U} 1}$ could be the marginal private benefit of the government of the producing country (user U1) and $\mathrm{MPB}_{\mathrm{U} 2}$ could be the marginal private benefit of the government of another country (user U2). Therefore, the marginal social benefit curve lies above any one marginal benefit curve (see Graph 1 below). This is very different from the case of a private good, where the first unit of a product consumed by user U1 is different from the unit of the product consumed by user U2. So the demand for official statistics is characterized by:

For an increment of quality in official statistics,

Marginal Social Benefit $=$ Vertical $\Sigma_{i}$ Marginal Private Benefit of User $i$ (for $i=1, \ldots, n$ )

The supply side for official statistics is provided by the Marginal Social Cost. The government of a country that is producing official statistics is presumably estimating the marginal social cost. However, in the context of externalities, the marginal social cost may be different from the marginal private cost - the marginal internal cost of Pigou [8]. In the specific case of official statistics the marginal private cost is the cost borne by the entity (government) actually producing the official statistics. If the production of a certain level of quality of official statistics involves a positive externality, the production of an extra increment of quality in such statistics reduces the cost of producing other goods/services. The producers of the other goods/services will benefit from an increase in their output for a given outlay or a reduction in their marginal cost. This is the marginal external cost of Pigou and in this case, of generation of quality in official statistics, it would be negative. This describes a production side externality of quality of official statistics.

Who are the other producers who are experiencing a reduction in their marginal cost from an additional increment in the quality of official statistics of Country A? They are producers of official statistics in other countries in the region and in regional institutions, especially if there is a degree of partnership and integration, as well as official statistics producers in countries around the world and in international institutions. The rationale behind the decrease in their marginal private costs from an extra increment in the quality of statistics in country $\mathrm{A}$ is as follows. If the quality of statistics in country A is low, then by association, country B's official statistics producer will have to work harder in order to avoid the perception of country B's official statistics being afflicted by the same predicament. Put differently, the producer of country B will have to work less hard to establish a given level of credibility (which is part of the quality of its official statistics) if the quality of official statistics in country $\mathrm{A}$ is increased by an increment.

Moreover, there is a quality increasing effect in other producers of official statistics given the same private inputs, in that higher quality statistics in one country will lead to higher quality statistics in another country when counterpart data are used in the production of official statistics. The more counterpart data are used, the greater the dependence on the quality of the output of other statistical producers. Of course, also the effect on official statistics producers at the regional level and the international level, who use the statistics of each country as input in producing their statistical output increases further the importance of these external marginal costs.

Thus the supply for official statistics is characterized by:

For an increment of quality in official statistics,

Marginal Social Cost $=$ Marginal Private Cost $+\Sigma_{j}$ Marginal External Cost of other producer $j$ (for $j=$ $1, \ldots, m)$.

Therefore, the marginal social cost of producing an increment of quality of official statistics in Country A is the vertical addition of the marginal private cost of the producer country A and the marginal external costs of the other producers discussed above. The implicit supply curve therefore for increments of quality in official statistics in country A is located below the one that would be estimated from the perspective of the producer Country A alone (see Fig. 1 below), as the government of that country may overstate the marginal social cost for a given level of quality of its official statistics.

The intersection of the Marginal Social Cost (MSC) line and the Marginal Social Benefit (MSB) line corresponds to the globally optimal quality of official statistics $\mathrm{Q}^{2}$ (Graph 1). The outcome is higher qual- 


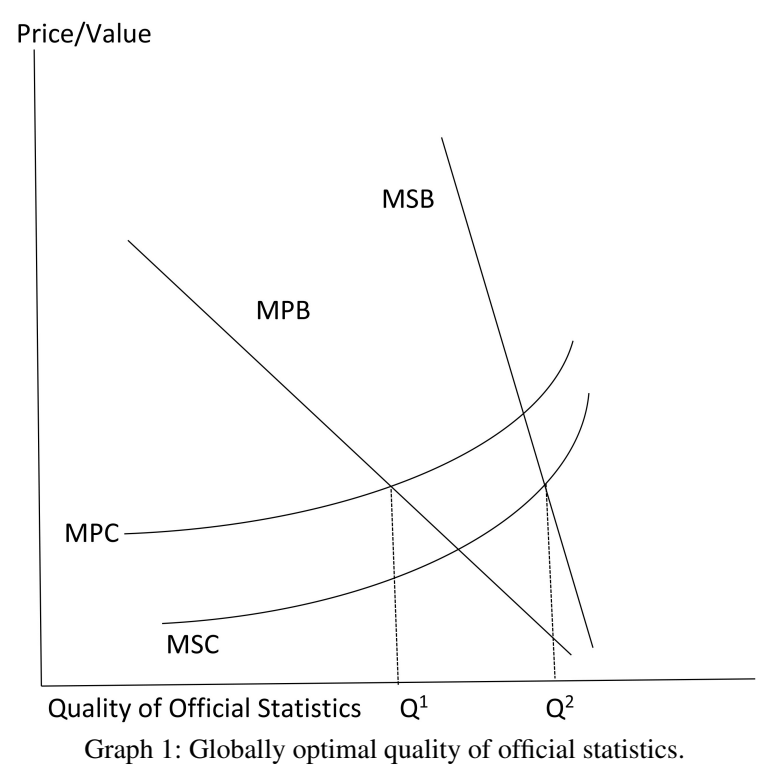

ity than the one provided by the intersection of the Marginal Private Benefit (MPB) and Marginal Private Cost (MPC), $\mathrm{Q}^{1}$, (or actually of MSB and MPC or of MPB and MSC). The net social benefit shown as the area between MSB and MSC up to their intersection is larger than the area between the MPB and MPC curves up to their intersection, as well as the area between MPB and MSC and the area between MSB and MPC.

Different types of global public goods require different types of international entities and legal frames to manage them [7]. Therefore the management of official statistics as a global public good would not normally be expected to fit into the mandate of existing international entities.

\section{Peer Reviews and the monitoring of the UNFP}

The solution that has been proposed by some for the monitoring of the UNFP is the use of regional institutions and initiatives to monitor and assess the implementation of the UNFP. In this context peer reviews have been proposed to be carried out and have been carried out on a by-and-large regional basis. Peer reviews of official statistics have thus taken place in the EU plus EFTA countries Iceland, Liechtenstein, Norway and Switzerland (within the European Statistical System) [9], in a number of African countries (African National Statistical Systems) [10], in certain countries of the Latin American and Caribbean Region [11], and in a few other countries around the world.
The focus and intensity of peer reviews carried out has varied across regions and over time. Peer reviews in the EU are presented [9], as part of the European Statistical System (EES) strategy to implement the European Statistics Code of Practice (CoP), which would be characterized as a derivative of the UNFP. The latest round of peer reviews in 2013-2015 had a somewhat different approach from the previous one that was carried out in 2006-2008, and covered all principles of the $\mathrm{CoP}$, the role of the National Statistical Institute as well as cooperation within and the level of integration of the ESS. The stated objective of the 2013-2015 round of peer reviews has been to enhance the integrity, independence and accountability of the statistical authorities, which make up the ESS. Peer reviews in African countries, on the other hand, have had a narrower focus - on the governance of the National Statistical System (NSS), its organization, strategic planning, service to users, funding and sustainability [10].

\subsection{Assessment of the adequacy of peer reviews as a means to a harmonized and robust assessment of the implementation of the UNFP}

The existence and use of peer reviews in certain regions of the world introduces the possibility for improvement in the monitoring of the UNFP as, in principle, such peer reviews should go beyond the selfmonitoring and self-assessment of the current system that applies globally. For example, the peer reviews that took place in the European Statistical System (ESS) in the period 2013-2015 provided professional and high quality assessments and recommendations regarding the implementation of international statistical standards that would not have been available to European countries by simply carrying out the selfassessments of the implementation of the UNFP every ten years. The ESS is better off on account of the conduct of the recent round of peer reviews.

Peer reviews may not be available as an option for monitoring the implementation of the UNFP around the world. Peer reviews have been applied over the past decade and a half to a relatively limited number of countries' official statistics producers. These countries have so far been characterized by strong regional integration ties or by being beneficiaries of regional collaboration/technical assistance initiatives. Thus the use of peer reviews cannot be seen as a widespread approach or as one that is evidently on the way to being adopted globally. Moreover, not all regions are as integrated or clustered as the EU and there may not be prospects for such integration or clustering. 
Peer reviews are also criticized for exactly what they are - reviews by peers. ${ }^{3}$ For example, the peer reviews of the ESS have been contrasted with the European System of Central Banks (ESCB) audit reviews, whose advantage over the peer reviews was presented to be that they "are carried out by a team of independent auditors, not (peer) statisticians, specialized in statistical issues" [12]. Thus it may be useful to consider having the evaluation of adherence to the UNFP carried out by an institution that would be seen as more detached than a group of peer reviewers and would face a lower risk of being accused of being "too cozy" with the people and institutions being reviewed. Considering a different approach to that of the peer reviews is also on account of not allowing the alleged coziness of the peer reviews being used as an excuse by institutions that produce official statistics not to participate in a robust monitoring and assessment of their statistical work.

There is also a need to have an international institution that a national official statistics producer can approach and request to be reviewed by it when there are challenges to the producer and the latter needs an evaluation that will not be easily dismissed. Regional peer reviews and regional institutions involved in quality control may be accused - and there are examples where they have been accused by detractors - of colluding with the national official statistics producer. Thus an institution that can be, and also credibly present itself as, detached needs to exist at the international level for addressing such cases. In this context, it should be noted that national-level institutions could be helpful in providing a review of institutional framework issues for official statistics production. However, they would not be as immune as an international institution to the risk of being perceived as either being influenced by the political system challenging the official statistics producer or colluding with the producer. The risk would be greater if such national-level institutions were predominantly composed by nationals. Finally, the assessment of such national-level bodies would carry less weight than that of an international institution.

Another question raised about peer reviews concerns harmonization of monitoring and assessment. The pro-

\footnotetext{
${ }^{3}$ This does not apply fully to the peer reviews that have taken place in African countries, in which policy makers participated in the review along with official statisticians from other countries in the region. Of course, the participation of policy makers as reviewers introduces risks regarding the appropriate sensitivity of these reviews to certain problems in the implementation of the UNFP.
}

cess of monitoring and assessing the implementation of the UNFP needs to be globally harmonized. The peer reviews themselves can be subject to criticism that they are not harmonized enough internally, i.e., within the same regional peer review initiative. It could therefore be argued that different peer review initiatives in regions around the world might produce even more variability in the review output. This is corroborated by the experience that the relatively few peer reviews that have taken place so far have had a varying focus and certain of these peer reviews did not necessarily cover all UNFP. The variability of the focus of the peer reviews, while it may serve certain purposes, leads away from the necessary harmonization in the monitoring of the implementation of the UNFP.

There are also instances where the practices of entire regions, or of regional institutions, might need to be reviewed and assessed. Moreover, the independence of regional institutions should be subject to review by someone outside the region, such as an international institution, to avoid the risk of conflict of interest as well as the perception of such a risk.

In conclusion:

- First, there is surely a need to go beyond the voluntary self-assessment questionnaire on the implementation of the UNFP currently put out and collected every decade. The self-monitoring and self-regulation approach would lead to a level of quality in official statistics that is not socially optimal from the perspective of the world community.

- Second, while peer reviews are making a positive contribution to the implementation of the UNFP, it is not the appropriate long-term solution to the issue of monitoring the implementation of the UNFP from a global point of view.

- Third, there is a need to manage the global public good of official statistics by setting up an appropriate international institution, which would be tasked with reviewing the adherence to international statistical principles. Such an institution would be set up drawing on accumulated experience with peer reviews and the institutional settings of national statistical systems.

\section{A vision of a global system of monitoring the implementation of the UNFP}

This second part of the paper aims to advance the discussion about aspects of an appropriate global system of monitoring the implementation of the UNFP. 
There is a need for an institution - rather than just a process - that will be the central operating vehicle of a system of monitoring the implementation of the UNFP. There are obviously various options regarding the institutional set up for that institution. ${ }^{4}$ Below are some broad proposals for consideration.

The envisaged institution would have to be an international institution covering in principle the implementation of the UNFP in all countries and regions of the world. It could be under the umbrella of the United Nations, but would have to be separate from political/policy organizations under the auspices of the UN and from their administrative hierarchies. In deciding the institutional setting and affiliation there would have to be consideration of any factors that would affect the speed and facility (including in the area of funding) in setting up the institution. Most importantly, there should be vigilance in ensuring that the institutional setting for the envisaged institution does not subject it to political influences and pressures and that its independence and effectiveness at every stage of its work is assured. ${ }^{5}$

By the same token, the governance of the institution would be a critical issue. The large international experience accumulated in setting up audit institutions and putting in place safeguards for the independence of auditors will be an important input in determining the appropriate governance of the envisaged institution. Regarding accountability mechanisms, some of those highlighted by the global administrative law project [7] could also be usefully considered. They could inter alia include transparency and access to information, notice and comment procedures, reason-giving requirements, substantive standards that must be met, independent review, and engagement with and oversight through private groups.

The envisaged institution would be producing a service for the global community, including inter alia national governments, regulators, the markets, rating agencies, research institutions, international institutions and the broad public of the world's countries.

\footnotetext{
${ }^{4}$ Malaguerra et al. [4] have made the suggestion that an inventory of the compliance of national statistical offices with the provisions of the UNFP on the basis of data in the public domain be carried out by an independent research institute or scientific foundation. The present paper argues for a dedicated international institution with a robust monitoring mandate.

${ }^{5}$ The broad issue of the statistics-related work within international organizations being organized in a way that gives that work the relevant professional independence needed has been mentioned in Ljones [13].
}

Thus the modalities of funding of the operations of the institution would need to take into account this broad array of beneficiaries. The modalities of funding would need to avoid ceding inappropriate authority to funding sources, and thus avoid any risk of influence on the decisions and the effectiveness of the institution.

The main function of the envisaged institution would be the regular review of all countries' official statistics with a view to assessing implementation of the UNFP. The institution could be set up automatically with this mandate in its statutes, with an opt-out rule, as opt-out rules generate much broader participation than do optin rules [7]. The review of each country's official statistics would be as regular as Article IV consultations of the International Monetary Fund (i.e., annually or biennially), to ensure that the monitoring can be sufficiently frequent so as to preempt as much as possible the emergence of pressures to not apply the UNFP and to address as early as possible emerging problems in the implementation of the UNFP. This would require an adequate number of well qualified professional staff. The staff would be drawn from around the world solely on the basis of professional criteria and most would have prior experience in the production of official statistics or of statistics more broadly. However, the institution would also seek professionals with experience in auditing, rating, certification, and quality assurance, as well as experience on the user side of official statistics - whether government, research community or the private sector - and in the academic field of statistics.

The experience of the IMF, with its Reviews of Standards and Codes (ROSCs), as well as the experience of national setups, such as the work of the UK Statistics Authority, provide models certain elements of which could be used in devising the modalities of operation of the new international institution. Review teams whose composition would be renewed on a regular basis would review the countries' official statistics and produce regular reports. There would need to be a robust internal review structure that would ensure the harmonization of application of the relevant criteria across reviewing teams and countries, with clarity on decision making roles and processes regarding final assessments. It would be essential that review operations be based in the institution and the majority of the work of the reviews of the implementation of the UNFP be carried out by the permanent staff of the institution. However the institution could also draw on a diverse pool of professionals with relevant experience from around the world to assist it to conduct its operations and continuously enrich the output of its human capital. 
The envisaged international institution would conduct a review of a country's official statistics production on the basis not only of self-assessment questionnaires filled out by the country's national statistics office and policy authorities, but also verification procedures via on site visits at the seat of the reviewed statistical authorities and detailed discussions with statistical producers, as well as surveys of and discussions with the various types of users of statistics (nationally and internationally) and data providers, discussions with representatives of the various branches of the national government, consultations with nationallevel statistical bodies, regional statistical authorities and bodies, etc. The institution would also carefully and independently consider, as inputs, the results of peer reviews and any other supranational monitoring of statistical principles that may have taken place in the case of the country, as well as relevant reports produced by national statistical bodies. There would thus be complementarity between peer reviews and regional systems of monitoring implementation of statistical principles on the one hand and the proposed global system of monitoring of the UNFP on the other hand, with salutary effects on the quality and accountability of both.

The nature of the reviews by the international institution would be rigorous and akin to auditing. The experience of carrying out audits and activities such as credit rating would be brought to bear in devising a robust process. Essential aspects of the work of the institution would be meticulous examination with verification and methodical follow-up monitoring. Rating would have to be part of the review output. The reference point of the reviews would be the UNFP. However, the tools used would include the Implementation Guidelines of the UNFP, which could be updated and further developed and operationalized as necessary, as well as other quality assessment framework tools that would be adapted and standardized for the purpose at hand.

As noted above, the review of countries' official statistics would not be compulsory, as countries could opt out. However countries would be encouraged in various ways to submit their official statistics to the review of the institution. Completion of the review by this institution could become a requirement of international governmental entities, such as the World Bank and the IMF or regional supranational bodies. It is nearly certain that the markets would look more favorably on those countries that subject their official statistics to review by the institution and even more so on those countries that are assessed to have a high degree of compliance with the UNFP in their production of official statistics. The markets would exert in their way significant pressure on countries to participate in the review process. The interest of the markets and of international and regional policy institutions in the output of the proposed institution would help keep the quality of that output high.

The points made above are also relevant to the issue of appropriate reaction, including possible sanctions, and enforcement when breaches of the UNFP are assessed to have taken place. Such appropriate reaction would not be in the mandate of the envisaged international institution, but would be carried out by other international and regional institutions on the policy side, with processes they will decide upon themselves, and by the markets through their reaction to the institution's assessments of the implementation of the UNFP. This highlights the fundamental point that the way to appropriate reaction and enforcement passes through the publication of the reviews of the envisaged institution and the transparency of its work.

While the central aim of the institution would be to conduct reviews of adherence to fundamental statistical principles by national statistical systems, the institution should also be available to conduct reviews of specific statistical issues/products. In addition it should be possible for official statistics producers (whether national or regional) to be reviewed for specific issues by the international institution on an ad hoc basis, with the triggers for such a review specified in the statutes of the institution, but surely with a view to minimizing the duration and degree of any damage to the confidence in official statistics and the implementation of the UNFP anywhere in the world.

Given that the mandate of the institution would be to review the adherence to the UNFP of national statistical systems, the review would not be confined to National Statistical Offices, but would encompass also Other National Authorities (ONAs) as producers of official statistics, including institutions such as Central Banks in their capacity as producers of official statistics. Moreover reviews of supranational statistical producers, such as Regional Statistical Authorities, would also be appropriate. Review of regional statistical producers and systems by the international institution would usefully complement the work of regional bodies mandated to review the implementation of UNFP and derivative codes of practice regionally.

The institution would be available to provide advice to the UN Statistics Division, Regional Statistical 
Authorities and National Statistical Offices on issues of implementation of the UNFP and related matters. The institution would also cooperate with regional and other supranational institutions (such as the European Statistical Governance Advisory Board) that have as a mandate the monitoring of the implementation of international statistical principles.

\section{Additional considerations}

An international institution and legal framework to manage a global public good such as official statistics and their quality is needed even if one considers that serious problems in the implementation of international statistical principles is something that afflicts only a few countries and such problems are the exception rather than the rule. Seeing the quality of official statistics as a "weakest link public good", akin to the global public goods of eradication of infectious diseases or of curtailing the proliferation of weapons of mass destruction, would still require international institutions and legal frameworks to effectively manage it [7].

An argument against the creation of the proposed international institution could be that there are serious breaches of the UNFP in very few cases and there is a relatively high level of compliance with the UNFP in the vast majority of cases, and thus the proposed international institution would not be helpful or necessary. However, the above premise is probably not accurate. The degree of compliance with the UNFP is most likely a continuum from very low to high compliance and, as discussed above, the degree of compliance on average for a country's official statistics is overstated by the current system of voluntary self-assessment. Therefore, an international institution that might be set up would not find itself in a situation where there are no or very few cases of weakness it could help address.

Another argument could be that an international institution would not be useful in monitoring the compliance with the UNFP of countries that have already achieved a relatively high degree of compliance. However, such an argument does not give adequate weight to the following points: First, a regular independent audit with rigorous follow up by an international institution would result in improvements to address remaining weaknesses and to align even more closely with international best practices than the current selfassessment system every ten years or even any regional peer-review that might take place every five or ten years. Second, compliance with international statistical principles is not something that is achieved once and for all, but is dynamic and needs to be actively maintained daily by the actions of official statistics producers and the political environments where the production of official statistics takes place. A standing international institution with a rigorous mandate would enable the maintenance of such a high degree of compliance and deter damage to the latter over time, as well as encourage adaptation to new circumstances (such as the emergence of "big data") more effectively than any long-cycle self-assessment or ad hoc peer review process.

The argument above points to the buttressing and protective effects on a high degree of compliance to the UNFP by the proposed international institution. This should be understood by countries with a high degree of compliance as an important benefit to them, not only on account of the benefit to them directly through the salutary effects on their official statistics over time and the "certification" of their high quality at a given moment in time, but also indirectly through the various externalities of other countries' official statistics that were discussed above. A country benefits from other countries' adherence to the UNFP and should thus be supportive of an international set-up that supports such adherence.

There is a possible argument that countries may see the proposed international institution as an unwelcome interference in their national affairs. If such perceptions exist and are put forward then obviously there is a need for an international institution such as the one proposed: an institution that would help take the production of official statistics from being an internal affair - "cuisine interne" - and thus subject to infringement of statistical principles, to being a transparent, internationally comparable and impartial production of a global public good.

The issue of cost of the proposed international institution would be a concern and would be presented as an argument against the creation of the proposed institution. Conducting reviews of potentially all countries' adherence to the UNFP on an annual or biennial basis with rigorous follow up could possibly require a budget similar to that of a mid-size country national statistics office. However, the cost to the international community (governments, markets and populations) arising from regional and global financial instability and contagion, lower volumes of trade and investment, lower economic growth, weaker responses to social, health and environmental problems, on account of problems 
obscured or compounded by unreliable and generally low quality official statistics, exceeds by many orders of magnitude the cost of setting up and operating the proposed international institution.

A question that might arise in trying to set up an international institution to rigorously and in a harmonized manner monitor the implementation of the UNFP is whether such an effort is bound to be confronted with demands for heavy compromises (for example on the assessment criteria and possible recommendations of such an institution) so as to cater to the different political and cultural approaches to the production of official statistics around the world. If such an issue were to arise, it would be further proof that the implementation of the UNFP currently is much more questionable than hoped for. Moreover, instead of discouraging the creation of the proposed international institution, any such demands, on account of political and cultural constraints on official statistics in many parts of the world, should serve as proof of the urgent need to set up the proposed institution with the proper robust mandate and rigorous operations indicated in this paper.

In this context, it should be pointed out that peer reviews organized on a regional basis, potentially reflecting different political and cultural approaches to the production of official statistics would run the risk of providing to users globally a false sense of implementation of the UNFP in some regions. For example, a political setting where independent statistical authorities would not be tolerated and political authority would have the last word on statistical methods, standards and procedures would simply not be compatible with UN Fundamental Principles 1 and 2. A regional peer review that would be constrained on account of political and cultural constraints not to recognize this incompatibility would actually be misleading and a hindrance in the effort to have effective monitoring of the implementation of the UNFP globally. It would also be legitimizing the potential perpetuation of breach of the statistical principles involved. Such problems would not arise with a properly set up international institution.

Finally, it should be pointed out that in a world where official statistics production would move away from the embrace of the executive branch of government with a view to further and sustainably strengthening the independence of statistical authorities, there will be a need for structures of accountability in the international area. An aspect of these structures of accountability would be the proposed international institution that reviews the implementation of the UNFP.

\section{Conclusions}

This paper has aimed to advance the discussion on the need for an international-global system of review and assessment of the implementation of the UN Fundamental Principles of Official Statistics. The paper has introduced an analytical argument of why official statistics and their quality is a "global public good." As such it needs to be managed appropriately at the global level so as to achieve a socially optimal outcome from the point of view of the world community. The paper has argued that while progress has been made over the past twenty years in promoting the UNFP with a view to achieving high quality of official statistics, the current system of monitoring the implementation of the UNFP and thus of the quality of official statistics in individual countries is severely limited. This is because it is effectively a system of voluntary self-assessment and self-monitoring and thus of limited reliability and usefulness. Moreover, the peer reviews that have taken place in some countries, although helpful, do not constitute, for a number of reasons, the appropriate long term solution to the issue of optimally managing the global public good of official statistics. The paper has argued instead that effective compliance monitoring of the implementation of the UNFP, through regular evaluation, verification, follow-up and published reports in the form of audits by an independent international institution at the global level is essential for rigorous, timely and harmonized implementation of the UNFP in the long run. The paper has discussed various aspects of setting up the proposed international institution and the global system of monitoring the implementation of the UNFP and has addressed a number of issues that may be raised regarding the proposed institution.

\section{Acknowledgements}

The author is grateful to Gerry O Hanlon and Geoffrey Woglom for comments on an early draft and to an anonymous reviewer for comments on the submitted paper. The views expressed herein and any errors are those of the author.

\section{References}

[1] United Nations. United Nations Fundamental Principles of Official Statistics, Implementation Guidelines, Final draft, subject to editing, January 2015. Available from: https:// unstats.un.org/unsd/dnss/gp/impguide.aspx. 
[2] J.L. Bodin, Remarks. High Level Forum on Official Statistics - UN Fundamental Principles of Official Statistics, 3 March 2014, United Nations, New York, United Nations Statistical Commission, United Nations [2014 March 21]. Available from: https://unstats.un.org/unsd/statcom/statcom_ 2014/seminars/High_Level_Forum/default.html.

[3] M. Bohata, UNFP - some implementation issues. High Level Forum on Official Statistics - UN Fundamental Principles of Official Statistics, 3 March 2014, United Nations, New York", United Nations Statistical Commission, United Nations [2014 March 21]. Available from: https://unstats.un.org/unsd/ statcom/statcom_2014/seminars/High_Level_Forum/default. html.

[4] C. Malaguerra and A.L. MacDonald, Statistics as instruments for prosperous, transparent and democratic societies, Statistical Journal of the IAOS 32 (2016).

[5] United Nations Statistics Division. Implementation of the Fundamental Principles of Official Statistics, Background document, $44^{\text {th }}$ Session of the Statistical Commission, 26 February-1 March 2013, 2013. Available from: https://unst ats.un.org/unsd/statcom/44th-session/documents/doc13/BGFP-E.pdf.

[6] W. Nicholson, Microeconomic Theory, Basic Principles and Extensions. Hinsdale, Illinois: The Dryden Press, 1978.

[7] G. Shaffer, International Law and Global Public Goods in a Legal Pluralist World. European Journal of International Law 23(3) (August 2012). Available from: http://www.ejil.org/ article.php? article $=2295 \&$ issue $=112$.
[8] H. Kohler, Intermediate Microeconomics, Theory and Applications. Glenview, Illinois: Scott, Foresman and Company, 1982.

[9] Eurostat, European Commission. Peer Reviews in the European Statistical System [Webpage on the Internet]. Available from: http://ec.europa.eu/eurostat/web/quality/peer-reviews.

[10] S. Blazyk, G. Charumbira, L. Diop, M. Strode and T. Williams, Peer Reviews of African National Statistical Systems, African Statistical Journal 10 (May 2010). Available from: https://www.paris21.org/sites/default/files/ASJ_Vol10 _peer_reviews.pdf.

[11] P. Martin-Guzman and M. Aguilera, Statistical governance in the Latin American and the Caribbean Region: Achievements and challenges, Statistical Journal of the IAOS 31 (2015).

[12] A. Schubert and C. Ahsbahs, The ESCB Quality Framework for European Statistics, Austrian Journal of Statistics 44 (April 2015). Available from: http://www.ajs.or.at/index.php/ ajs/article/viewFile/vol44-2-1/60.

[13] O. Ljones, Twenty years of the United Nations Fundamental Principles of Official Statistics: The present and an outlook into the future, Statistical Journal of the IAOS 31 (2015). 